\title{
INFLUENCE OF MICRO-HOLES ON RAKE FACE OF THE CARBIDE INSERT ON MACHINING PERFORMANCE
}

\author{
P Jeyapandiarajan ${ }^{1}$, M. Anthony Xavior ${ }^{1 *}$, P. Sasidharan ${ }^{2}$, Arnaud Duchosal $^{2}$ \\ ${ }^{1}$ Vellore Institute of Technology, School of Mechanical Engineering, Vellore, India \\ ${ }^{2}$ University of Tours, University of Orleans, INSA CVL, LaMe, Tours, France \\ ${ }^{\star}$ Corresponding author; e-mail: manthonyxaviour@vit.ac.in
}

\begin{abstract}
The performance of the PVD coated carbide insert with micro-holes is experimentally compared with that of the conventional inserts while machining Inconel 718 under Dry and MQL condition (Canola Oil, $0.25 \%$ $\mathrm{Gr}$ with Canola Oil). The machining performance of textured tool is found to be relatively good when compared to untextured tool in terms of the cutting force, surface roughness, flank wear and crater wear occurred on the cutting inserts. It is being inferred that Canola oil with $0.25 \% \mathrm{Gr}$-nanoparticle has improved the cutting force by $17.39 \%$, decreased the flank wear and surface roughness by $20 \%$ and $36.23 \%$ respectively while machining with the textured tool.
\end{abstract}

\section{Keywords:}

Inconel 718; Machining; Textured Insert; Wear

\section{INTRODUCTION}

Nickel based super alloys finds route in various applications right from crawlers to flyers, floaters to submerses [Courbon 2013a]. For the last two decades researchers had contributed a lot to the industry and research community by investigating the thermal conductivity, work hardenability, surface integrity, tool life and chip morphology. In spite of the researchers contributions till date, findings that can improve the machinability of this material are still way behind. Inconel 718 is considered to be a difficult - to - cut material [Kramer 2012] [Zhu 2013] and dry machining has resulted in higher cutting force, poor surface integrity and reduced tool life [Wang 2008]. The usage of flood cooling condition has drastically affected the health of workers and the Mother Nature [Shaw 1951]. Machining study was performed by applying various cutting conditions like Dry, MQL and Flood cooling and it was observed that MQL out performs the other conditions [Jeyapandiarajan 2017]. High pressure jet machining and cryogenic machining have contributed much in reduction of cutting force and surface integrity [Courbon 2011b]. Power consumption during those operation and the external unit setup cost for these process neutralizes with the machining cost of the material [Devillez 2011]. Use of MQL system during the machining process provides improved heat dissipation in a much faster way [Sugihara 2009]. Heat dissipation from the tool and workpiece interaction zone would bring better out come on the machined component. Researchers are much keen in increasing the surface area on the tool which could be more essential for the heat dissipation process. Surface texture on the component has been in practice for more than a decade in the field of automotive, boiler manufacturing, heat exchangers etc. [Etsion 2004]. Surface engineering technology has found route in the field of machining, improvising the tribological properties of the component [Evans 1999] [Bruzzone 2008].

In the current scenario, following a conventional cutting process has diverged results like high temperature distribution caused by the Chip-tool-workpiece interaction zones, higher tool wear, poor surface finish and high work hardenability especially for the material that are classified as difficult-to-cut. Such engineering issues are addressed and the cutting performance has been improved by using micro-texture on the surface of the tool. Micro-texture present on the tool causes reduction in the friction flow of the chip and also reduces the tool wear and also surface bearing capacity [Liu 2019] [Deng 2012]. Micro-texture tool has improved the tribological characteristics while machining Ti-6Al-4V [Ding 2018], whereas, while machining mild steel and aluminium alloy with microtextured tool, cutting force has decreased [Jesudass 2018]. During machining of Aluminium 5038 material it was reported that textured tool has lowered the BUE formation on the material [Kang 2018]. AISI316 material when machining with the surface texture tool it has reduced the frictional force caused by the rubbing action between tool and the chip mainly on the rake side of the tool. Improving the tribological properties by taking control of the frictional force which takes place on the sliding pairs was reported [Fang 2017] [Niketh 2017]. Taguchi technique helps in optimizing the best design for the texturing on the surface of the tool [Sivaiah 2019]. Texture development on the 
surface of the tool had given encouraging results on tool characteristics, wear resistance and also towards antiadhesiveness [Sugihara 2009a]. CBN tool with microgrooves has drastically reduced the tool retreat and also tool life under high speed machining. It was also reported that dense layer of work piece material is formed on the flank side of the tool [sugihara 2012]. Hybrid texture tool having circular pit holes and linear grooves has significantly reduced the cutting zone temperatue, tool flank wear and surface roughness [Sivaiah 2020]. Many researchers had aimed to study the surface topography's role in machining various work materials with suitable tool materials and its effects. But designing the geometry of the texture for machining difficult - to - machine material is still in infancy stage. Present study focuses on evaluating the performance of the untextured tool and textured tool while machining Inconel 718.

\section{EXPERIMENTAL SETUP}

Turning operation was performed in the Computer Numerical Control (CNC) machine: ACE Simple Turn 5075 with a spindle speed varying from 50 to $4000 \mathrm{rpm}$ as shown in the fig. 1. Inconel 718 cylindrical bar of diameter $28 \mathrm{~mm}$ and length $500 \mathrm{~mm}$ is used for the experimentation. The chemical composition of Inconel 718 material is presented in table. 1 and the same values were recorded when tested the specimen with SPECTRO - xSPORT portable device. Cutting force is one of the most important output characteristic to be studied while machining Inconel 718. Cutting force data were recorded by Kistler dynamometer Type 9257B that suits to measure the 3 orthogonal force component converting a small dynamic variation to large scale values. The setup of Type 9257B Kistler dynamometer is shown for better understanding in fig. 2 . Surface roughness measurements were carried out using Marsurf GD120 surface roughness tester. Probe arm moves in $x$ direction on the surface of the specimen for $4 \mathrm{~mm}$ and the readings are recorded at regular interval of 120 degree as shown in fig. 3. PVD coated carbides (KC 5010) are procured from M/s Kennametal Tools. Fig. 4 (a \& b) shows the images of the textured and untextured tool respectively. Fig. 4 shows the textured and untextured tool. Arc of the dimples seen in textured tool is generated keeping the centre of the circle towards tool nose side. Nose tip is the region in general come in contact with the work material during the machining operation. In order to maintain the strength and stability of the tool, arc is made towards the nose side. Three dimples of size 100 micron diameter and 100 micron depth, were made on the tool insert as shown in the fig. $4 \mathrm{a}$. Arc length of the dimples were made at an angle of $60^{\circ}$. Dimple creation requires laser treatment that is performed at pulsing frequency of $20 \mathrm{kHz}$.

Turning operation was carried out by using textured and untextured tool and their effects were studied on the cutting force, surface roughness and the tool wear. Cutting parameters also play a major role in deciding the outcome of the machining process. By increasing the number of variables the complexity to identify the most important
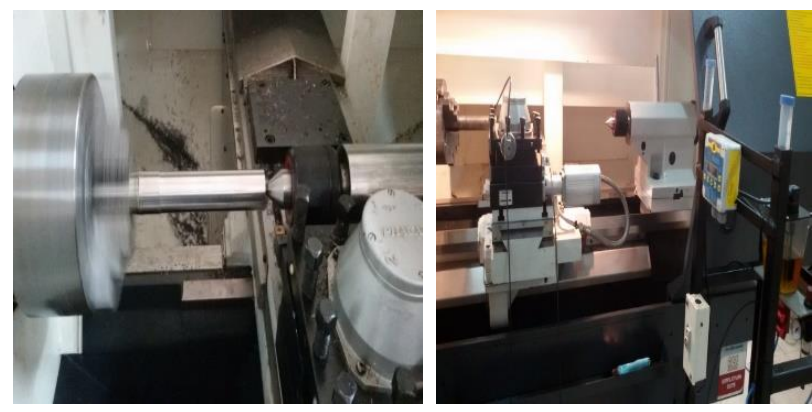

Fig. 1. CNC Simple Turn 5075 while turning Inconel 718

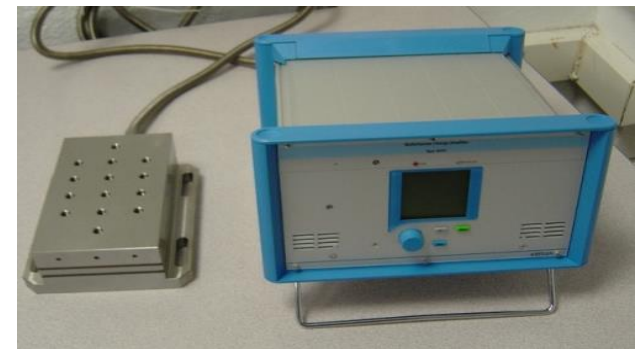

Fig. 2. Kistler Dynamometer Type 9257B for measuring the cutting force while machining.

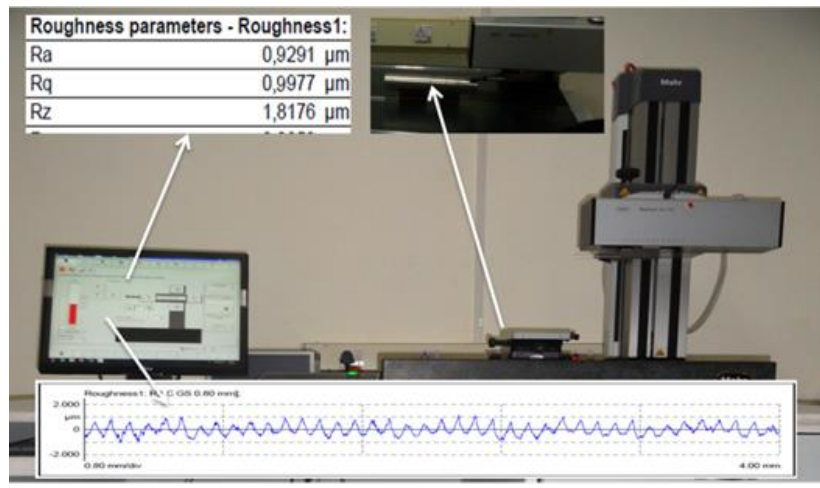

Fig. 3. Marsurf Surface roughness tester

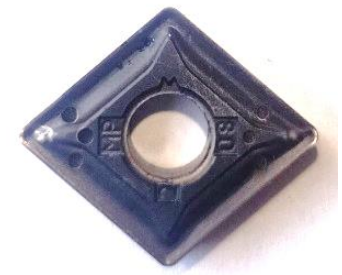

a) Micro-Textured

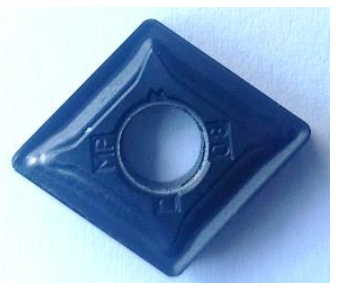

b) Un-Textured
Fig. 4. PVD Coated carbide with a) Micro textured b) Un-textured

factor that contribute to that changes remain difficult. For this reason the cutting speed is varied, while feed rate and depth of cut are kept constant throughout the experiments. Cutting parameters for machining the Inconel 718 are presented in table 2. Minimum Quantity lubricant (MQL) system has been developed indigenously to handle canola

Table. 1 Chemical Composition of Inconel 718

\begin{tabular}{|c|c|c|c|c|c|c|c|c|c|c|c|c|}
\hline \multirow{2}{*}{$\begin{array}{c}\text { Inconel } \\
718\end{array}$} & $\mathrm{Ni}$ & $\mathrm{Cr}$ & $\mathrm{Fe}$ & $\mathrm{Mo}$ & $\mathrm{Nb}$ & $\mathrm{Co}$ & $\mathrm{Mn}$ & $\mathrm{Cu}$ & $\mathrm{Al}$ & $\mathrm{Ti}$ & $\mathrm{Si}$ & $\mathrm{C}$ \\
\cline { 2 - 12 } & $50-55$ & $17-21$ & balance & $2.8-3.3$ & $4.75-5.5$ & 1.0 & 0.35 & $0.2-0.8$ & $0.65-1.15$ & 0.3 & 0.35 & 0.08 \\
\hline
\end{tabular}

MM Science Journal | 2021 | NOVEMBER - Special Issue on HSM2021 
oil. Canola oil is a vegetable based oil extracted from the rapeseed and find its application in many industries as biofuel. Addition of nanoparticle to the canola oil increases tribological behaviour during machining, in addition, conductivity and sustainability remain in better side [Reeves 2017].

Table 2. Machining parameters and their values

\begin{tabular}{|l|l|}
\hline Parameters & Values \\
\hline Cutting speed & $80 \mathrm{~m} / \mathrm{min}, 110 \mathrm{~m} / \mathrm{min}, 140 \mathrm{~m} / \mathrm{min}$ \\
\hline Depth of cut & $1.0 \mathrm{~mm}$ \\
\hline Feed Rate & $0.16 \mathrm{~mm} / \mathrm{rev}$ \\
\hline PVD Coated Tool & Textured, Un Textured \\
\hline Cutting Condition & $\begin{array}{l}\text { Dry, MQL condition (Canola Oil, } \\
0.25 \% \text { Gr with Canola Oil) }\end{array}$ \\
\hline
\end{tabular}

\section{RESULTS AND DISCUSSION}

\subsection{Cutting Force Analysis}

Cutting forces were recorded online by using Kistler dynamometer while turning the specimen under different machining conditions. From fig. 5 . it can be inferred that cutting force for the untextured tool (Dry condition) increases as the cutting speed increases from $80 \mathrm{~m} / \mathrm{min}$ to $140 \mathrm{~m} / \mathrm{min}$. As the cutting speed is increasing the friction force increases as the metal to tool contact volume increases drastically. During the MQL machining canola oi is allowed to fall on the textured area of the tool.

\section{CUTTING FORCE (N)}

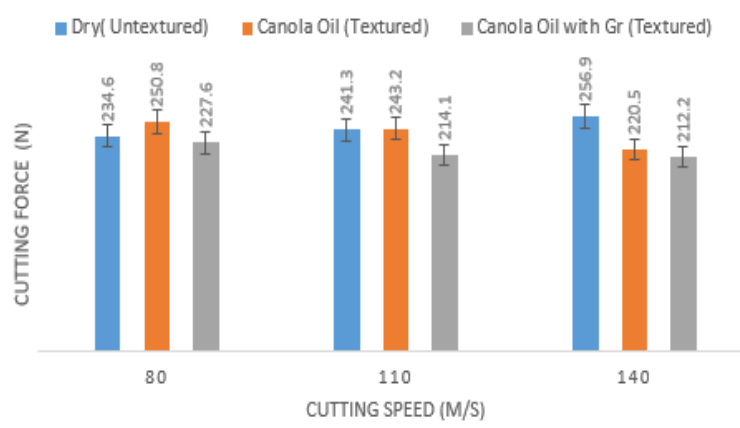

Fig. 5. Cutting force analysis while machining at various cutting speeds.

MQL system for applying canola oil is set to have a flow rate of $10 \mathrm{ml} / \mathrm{min}$ using a control valve. This controlled flow helps in utilising a reasonable quantity of canola oil for every trial. When the Canola oil is spilled on the tool, heat dissipation increases because of the conduction and convection processes. This in general increases the temperature distribution at the tool - workpiece interaction area. Lowering the temperature at the tool tip will allow the coated tool to sustain for longer period. Canola oil present in the dimples of the tool act as reservoir or heat sink to fade away the heat generated at the tool tip or nose region. This phenomenon causes the reduction in the cutting force while machining with canola oil. This local phenomenon was flavoured by using graphene ( $\mathrm{Gr}$ ) particles which in nature has high thermal conductivity. Canola oil with $0.25 \%$ of $\mathrm{Gr}$ stir the process of thermal dissipation in much faster way and helps in protecting the tool from deteriorating. Viscosity of the fluid also contributes in the thermal dissipation. Canola oil has a viscosity of $37.4555 \times 10^{-6} \mathrm{~m}^{2} / \mathrm{s}$ and, when Graphene is added by $0.25 \%$ the viscosity falls to 34.0629 $x 10^{-6} \mathrm{~m}^{2} / \mathrm{s}$, increasing the wettability of the oil. All these reasons have resulted in lower cutting force when compared with the other two cutting conditions. Canola oil with $0.25 \% \mathrm{Gr}$ has reduced the cutting force by $17 \%$ as the cutting speed increases.

\subsection{Tool Wear Analysis}

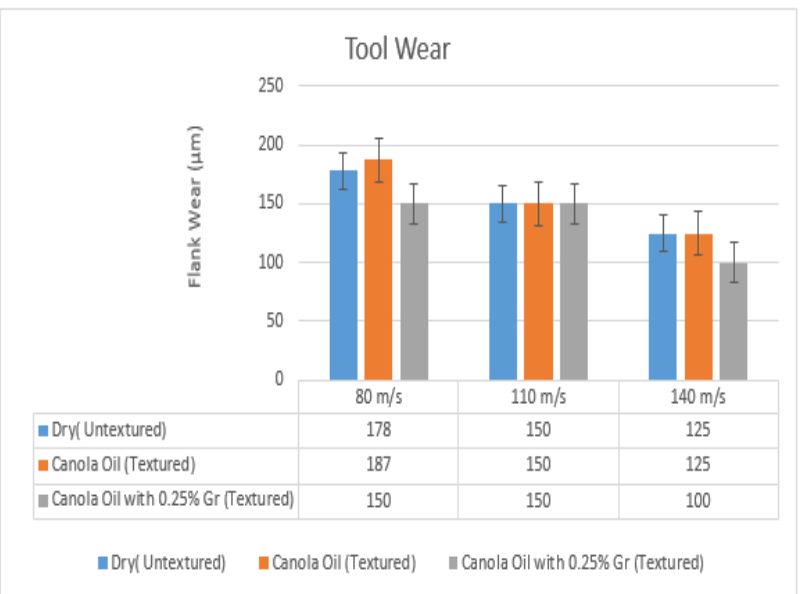

Fig. 6. Tool wear study on machining Inconel 718 (Flank wear)
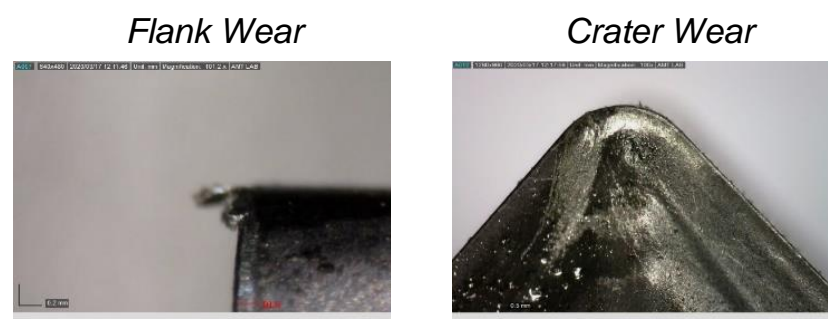

a) Cutting Speed $80 \mathrm{~m} / \mathrm{min}$ - Flank wear - $187 \mu \mathrm{m}$ Crater wear shows visible scratch pattern towards the center of the flank.
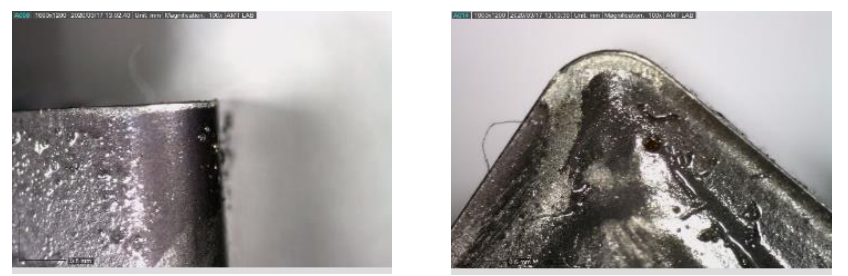

b) Cutting Speed $110 \mathrm{~m} / \mathrm{min}$ - Flank wear - $150 \mu \mathrm{m}$, Crater wear shows more visible scratch pattern with adhesion of chip on the tool.
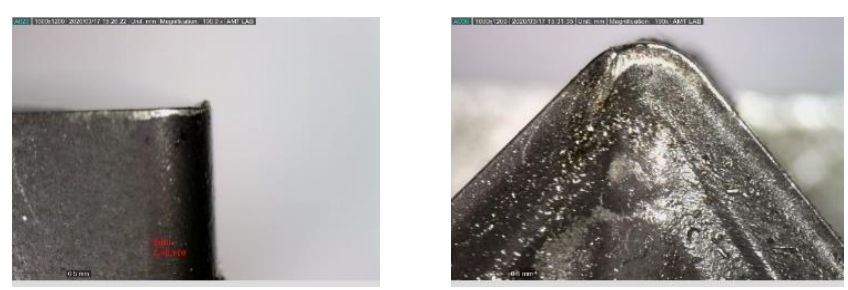

c) Cutting Speed $140 \mathrm{~m} / \mathrm{min}$ - Flank wear - $125 \mu \mathrm{m}$, Crater wear shows maximum visible scratch pattern with chipping and notching at tool edge, also causes stress cracking and deformation.

Fig. $7(a, b, c)$ Tool wear study for dry machining (untextured tool) of Inconel 718 with various cutting speed. 
When there is a relative motion between the two materials, it would predominantly get into the rubbing action causing wear and tear of the material which is inevitable during machining. Study and precautionary steps can control the wear that occurs on the tool material. Tool wear in general are engrossed with flank wear and crater wear as they come in interaction with the workpiece and chip respectively.

Flank Wear

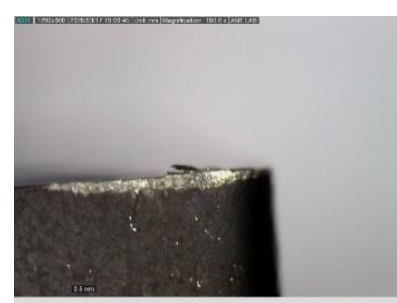

a) Cutting Speed $80 \mathrm{~m} / \mathrm{min}$ - Flank wear - $178 \mu \mathrm{m}$ Crater wear is represented as narrow, visible scratch pattern towards the center of the flank.
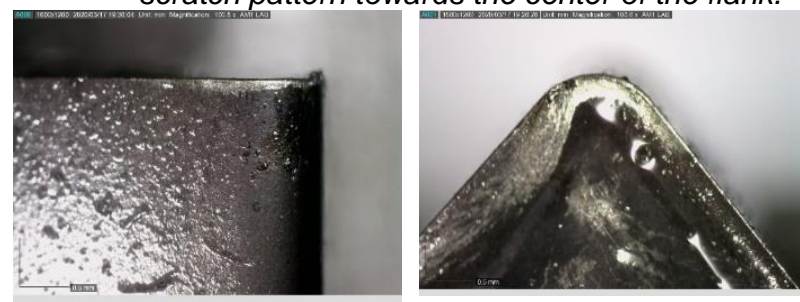

b) Cutting Speed $110 \mathrm{~m} / \mathrm{min}$ - Flank wear - 150 $\mu m$, No traces of visible crater wear or scratch pattern.
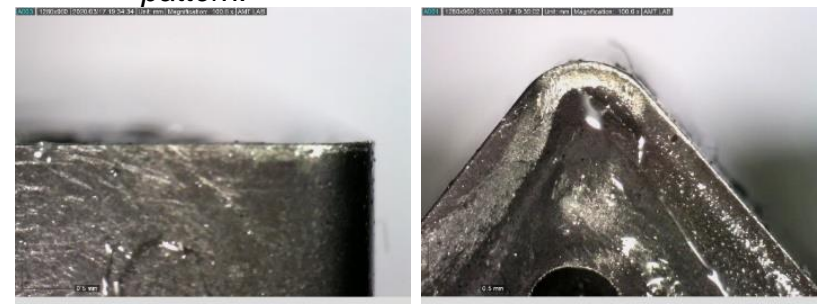

c) Cutting Speed $140 \mathrm{~m} / \mathrm{min}$ - Flank wear - 125 $\mu \mathrm{m}$, Clear edges of the tool are visible. No traces of crater wear, no indication of chipping and notching at tool edge, no deformation and stress cracks.

Fig. $8(a, b, c)$ Tool wear study for canola oil -machining condition of Inconel 718 with various cutting speed.

Fig. 6. indicates that the flank wear remain low while using canola oil with $0.25 \%$ graphene. When the cutting speed is $80 \mathrm{~m} / \mathrm{min}$ the canola oil with $0.25 \%$ Graphene provides lower flank wear of 150 microns. As the cutting speed increases the value drops to 100 microns due to the presence of the graphene nanoparticles which remain as good thermal conductor to absorb the heat generated at the primary and secondary zones of interaction. Crater wear can be seen on the rake face of the tool, which exists only during the dry machining conditions. While machining in the presence of canola oil, the flank wear reduces to a larger scale and when graphene nanoparticles are used the values drops further leading to a minimum of 100 microns at high cutting speed of $140 \mathrm{~m} / \mathrm{min}$.

Fig. 7. Shows the tool wear study of the Inconel 718 turned during the dry condition. PVD Coated carbide tool has higher flank wear at lower cutting speed and decreases as the cutting speed increases. Flank wear shown in fig. 8 and 9 reveals that there is steady drop in the value from 178 to $100 \mu \mathrm{m}$. Graphene nanoparticle forms a layer around the tool nose region and dimple region providing complete transfer of heat through conduction and convection. Notches, chipping, scratch marks, sticking of chip particles are noticeable on the rake side while turning at dry condition as shown in fig. 7. Crater wear is found to be nullified while machining with canola oil and canola oil - $0.25 \% \mathrm{Gr}$ condition as shown in fig. 8 and 9 respectively.
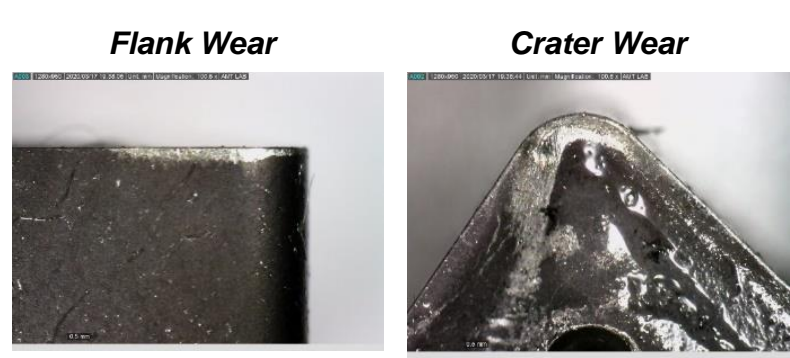

a) Cutting Speed $80 \mathrm{~m} / \mathrm{min}$ - Flank wear - $150 \mu \mathrm{m}$ Crater wear is represented as narrow, visible scratch pattern and graphene particle over the tool edge.
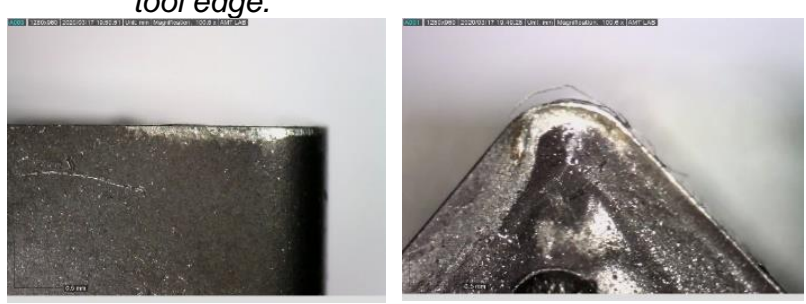

b) Cutting Speed $110 \mathrm{~m} / \mathrm{min}$ - Flank wear - 150 $\mu \mathrm{m}$, Crater wear is represented as a tiny, visible scratch pattern, tool profile remains perfect.
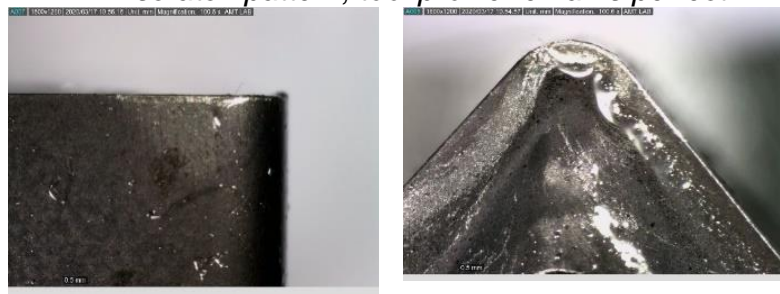

c) Cutting Speed $140 \mathrm{~m} / \mathrm{min}$ - Flank wear - 100 $\mu \mathrm{m}$, Clear edges of the tool are visible, with small vloume of graphene deposited on the surface.

Fig. $9(a, b, c)$ Tool wear study for canola oil with $0.25 \%$ $\mathrm{Gr}$-machining condition of Inconel 718 with various cutting speed.

Notches, scratch marks, sticking of chip particles were suppressed by the Gr- nanoparticle fluids present. Grnanoparticles increase the wettability of canola oil by spreading the oil over the rake face. Generated chips flow over these Gr-nanoparticle reducing the impeachment of chip on the rake face directly as a result notch wear and scratch marks are prevented. This is more evident while looking into crater wear shown in fig. 9.

\subsection{Surface Roughness}

Surface finish determines the life of the products used in rotary components like shafts and bearings. Surface roughness measurements were made using Marsurf GD 120 instrument and the results are presented in fig. 10 . Surface roughness decreases with the presence of Grnanoparticle by increasing the heat conducted from the chip and workpiece on the tool. Figure 10 infers that roughness value improves as the cutting speed increases from 80 $\mathrm{m} / \mathrm{min}$ to $140 \mathrm{~m} / \mathrm{min}$. As the cutting speed increases the cutting forces decreases lowering the surface roughness to 0.5924 micron. Low thermal conductive of the workpiece 
material due to its high specific latent heat soften the material at higher speed increasing the surface roughness value. Gr-nanoparticle with good thermal conductivity reduces the thermal softening at the tool region avoiding the BUE formation. These factors results in lowering the surface roughness value at the higher cutting speed specially while machining with Gr-nanoparticles. Surface roughness has been improved by $36.23 \%$ when machined with $0.25 \% \mathrm{Gr}$-nanoparticle at a higher cutting speed of $140 \mathrm{~m} / \mathrm{min}$

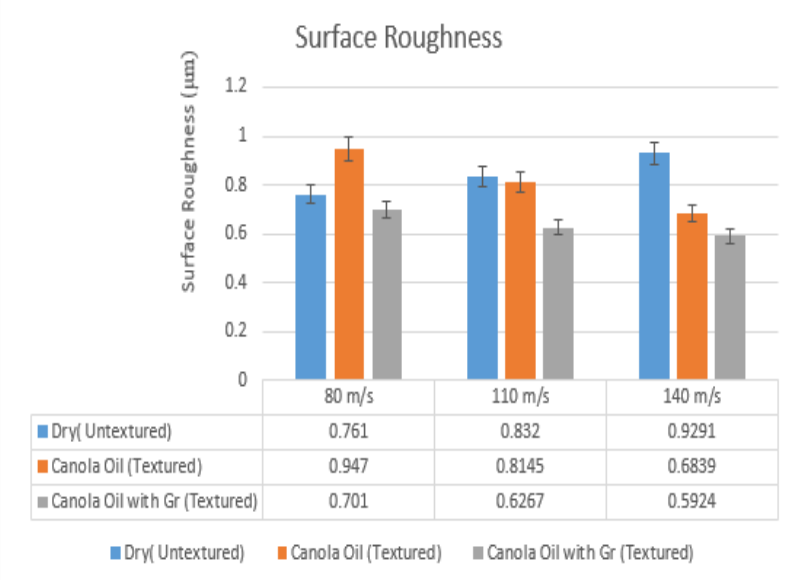

Fig. 10. Surface Roughness observed for various cutting conditions.

\section{SUMMARY}

Inconel 718 machining by varying the cutting speed from 80 $\mathrm{m} / \mathrm{min}$ to $140 \mathrm{~m} / \mathrm{min}$ keeping feed and depth of cut at a constant level created a drastic change in the cutting force, flank wear and surface roughness. The experimental results indicate that the performance of the textured tool is relatively good when compared to the untextured tool in terms of the cutting force, surface roughness and tool wear. Canola oil with $0.25 \%$ Gr-nanoparticle has improved the cutting force by $17.39 \%$, decreased the flank wear by $20 \%$ and surface roughness by $36.23 \%$ when machined with the textured tool. Crater wear remains negligible which is a good indication for a prolonged tool life of textured tool. Canola oil has improved the thermal conductivity of the tool and also protect the tool from chip scratch by forming a uniform cover over the tool tip. Canola oil with easy availability and environmental friendly remains sustainable for the MQL system.

\section{REFERENCES}

[Bruzzone 2008] Bruzzone AAG, Costa HL, Lonardo PM, Lucca DA. Advances in engineered surfaces for functional performance. Ann CIRP 2008;57(2):750-69, http://dx.doi.org/10.1016/j.cirp.2008.09.003.

[Courbon 2013a] Courbon, C.; Pusavec, F.; Dumont, F.; Rech, J.; Kopac, J. Tribological Behaviour of Ti6Al4V and Inconel718 under Dry and Cryogenic conditionsApplication to the Context of Machining with Carbide Tools. Tribol. Int. 2013, 66, 72-82.DOI: 10.1016/j.triboint.2013.04.010

[Courbon 2011b] Courbon, C., Sajn, V., Kramar, D., Rech, J., Kosel, F., and Kopac, J., "Investigation of Machining Performance in High Pressure Jet Assisted Turning of Inconel 718: A Numerical Model,"; Journal of Materials Processing Technology 211, pp. 1834-1851(2011).
[Deng 2012] Deng JX, Wu Z, Lian YS, Qi T, Chen J. Performance of carbide tools with textured rake-face filled with solid lubricants in dry cutting processes. Int J Refract Met H 2012; 30:164-72. doi: 10.1016/j.ijrmhm.2011.08.002

[Devillez 2011] Devillez, A., Coz, G. Le., Dominiak, S., and Dudzinski, D., "Dry Machining of Inconel 718, Workpiece Surface Integrity,"; Journal of Materials Processing Technology, 211, pp. 1590-1598 (2011).

[Ding 2018] Ding Y, Yang LJ, Cheng B, Wang XL, Wang Y, Xie $H$. Investigations on fem- to second laser-modified micro groove-textured cemented carbide YT15 turning tool with promotion in cutting performance. Int $\mathrm{J}$ Adv Manuf Technol 2018;96:1-13. doi: 10.1007/s00170-018-1906-0.

[Etsion 2004] Etsion I. Improving tribological performance of mechanical components bylaser surface texturing. Tribol Lett 2004;17(4):733-7,http://dx.doi.org/10.1007/s11249004-8081-1.

[Evans 1999] Evans CJ, Bryne JB. Structured textured or engineered surfaces. Ann CIRP1999;48(2):541-56, http://dx.doi.org/10.1016/S0007-8506(07)63233-8

[Fang 2017] Fang ZL, Toshiyuki O. Cooling performance of micro-texture at the tool flank face under high pressure jet coolant assistance. Precis-Eng 2017;49:41-5. doi: 10.1016/j.precisioneng.2017.01.008 .

[Jesudass 2018] Jesudass Thomas, S.; Kalaichelvan, K. Comparative Study of the Effect of Surface Texturing on Cutting Tool in Dry Cutting. Mater. Manuf. Process. 2018, 33(6), 683-694. DOI: 10.1080/10426914.2017.1376070.

[Jeyapandiarajan 2017] Jeyapandiarajan, P., and M. Anthony Xavior. "Experimental Investigations on the Machinability of Inconel 718 Under Different Cutting Conditions." 中國機械工程學刊 38, no. 3 (2017): 295-304.

[Kang 2018] Kang, Z.; Fu, Y.; Chen, Y.; Ji, J.; Fu, H.; Wang, $\mathrm{S}$.; Li, R. Experimental Investigation of Concave and Convex Micro-Textures for Improving Anti-Adhesion Property of Cutting Tool in Dry Finish Cutting. Int. J. Precis. Eng. Manuf. Green Technol. 2018, 5(5), 583-591. DOI:10.1007/s40684-018-0060-3.

[Kramer 2012] Kramer A, Lung D, Klocke F. High performance cutting of aircraft and turbine components. AIP Conf Proc 2012;1431:42532,http://dx.doi.org/10.1063/1.4707592.

[Liu 2019] Liu X, Liu Y, Li L, Tian Y. Performances of microtextured WC-10ni3al cemented carbides cutting tool in turning of ti6al4v. Int J Refract Met-H 2019; 84:104987. doi: 10.1016/j.jijmhm.2019.104987.

[Niketh 2017] Niketh S, Samuel GL. Surface texturing for tribology enhancement and its application on drill tool for the sustainable machining of titanium alloy. J Clean Prod 2017;167:253-70. doi: 10.1016/j.jclepro.2017.08.178 .

[Reeves 2017] Reeves, Carlton J., and Pradeep L. Menezes. "Evaluation of boron nitride particles on the tribological performance of avocado and canola oil for energy conservation and sustainability." The International Journal of Advanced Manufacturing Technology 89, no. 912 (2017): 3475-3486.

[Shaw 1951] Shaw, M. C.;Pigott, J.D.;Richardson,L. P. Effect of Cutting Fluid upon Chip-Tool Interface Temperature. Trans. ASME. 1951, 71(2), 45-56.

[Sivaiah 2019] Sivaiah, P.; Bodicherla, U. Effect of Surface Texture Tools and Minimum Quantity Lubrication (MQL) on Tool Wear and Surface Roughness in CNC Turning of AISI 52100 Steel. J. Inst. Eng. Ser. C. 2019, 1-11. DOI: 10.1007/s40032-019-00512-2. 
[Sivaiah 2020] P. Sivaiah, Venkata Ajay Kumar G, Muralidhar Singh M \& Harinandan Kumar (2020): Effect of novel hybrid texture tool on turning process performance in MQL machining of Inconel 718 superalloy, Materials and Manufacturing DOI:10.1080/10426914.2019.1697444

Processes,

[Sugihara 2009] Sugihara T, Enomoto T. Development of a cutting tool with anano/micro-textured surfaceimprovement of anti-adhesive effect byconsidering the texture patterns. Prec Eng 2009;33(4):4259,http://dx.doi.org/10.1016/j.precisioneng.2008.11.004.

[Sugihara 2009a] Sugihara T, Enomoto T. Development of a cutting tool with a nano /micro-textured surfaceimprovement of anti-adhesive effect by considering the texture patterns. Prec Eng 2009;33(4):4259,http://dx.doi.org/10.1016/j.precisioneng.2008.11.004.
[Sugihara 2012] Sugihara T, Enomoto T. Improving antiadhesion in aluminum alloy cutting bymicro stripe texture. Prec Eng 2012;36(2):229 37,http://dx.doi.org/10.1016/j.precisioneng.2011.10.002.

[Wang 2008] Wang J, Zhang Q. A study of highperformance plane rake faced twist drills. part I: geometrical analysis and experimental investigation. Int $\mathrm{J}$ Mach Tools Manuf 2008;48:1276-85

doi:

10.1016/j.ijmachtools.2008.03.005

[Zhu 2013] Zhu D, Zhang $X$, Ding $H$. Tool wear characteristics in cutting of nickel-based superalloys. Int $\mathrm{J}$ Mach Tools Manuf 2013;64:6077,http://dx.doi.org/10.1016/j.jimachtools.2012.08.001. 